\title{
Prototipe Cscm (Coin Sorting And Counting Machine) Berbasis Arduino Uno R3 Studi Kasus : Koperasi Melati
}

\author{
Agus Suheri ${ }^{1}$,Widi Juniarti Setiawan ${ }^{2}$ \\ Program Studi Teknik Informatika \\ Fakultas Teknik Universitas Suryakancana \\ agussuheri@unsur.ac.id ${ }^{1}$,widijunia@gmail.com ${ }^{2}$
}

\begin{abstract}
Abstrak
Arduino merupakan perangkat keras sekaligus perangkat lunak yang memungkinkan siapa saja melakukan pembuatan prototipe suatu rangkaian elektronika yang berbasis mikrokontroler dengan mudah dan cepat. Arduino Integrated Development Equipment (Arduino IDE) adalah perangkat lunak yang digunakan untuk mengembangkan program dan memungkinkan program diunggah ke papan Arduino. Papan arduino merupakan papan elektronis yang berisi mikrokontroler berbasis ATMega, sedangkan mikrokontroler adalah sebuah keping (integrated circuit) yang mengandung prosesor alias sang pemroses dan sekaligus memori yang berguna untuk menyimpan data.

Transaksi yang menggunakan uang koin biasanya membutuhkan waktu yang lebih lama dan tingkat kerumitan yang lebih tinggi dibandingkan dengan menggunakan uang kertas biasa. Sebab lebih banyaknya elemen yang dihitung. Bahkan sering sekali terjadi kesalahan dalam penghitungan dan penyortiran uang koin tersebut. Dengan memanfaatkan teknologi mikrokontroler, yaitu menggabungkan Arduino dengan Sensor Infrared, Motor Servo, Motor DC, LCD 20x4, I2C, dan Keypad 4x4 nantinya akan menjadi CSCM (Coin Sorting and Counting Machine) yang dapat menghitung dan menyortir uang koin secara otomatis. Hasil penghitungan dan penyortiran uang koin akan ditampilkan pada $L C D$.

Pada penelitian ini diharapkan dapat membantu transaksi menggunakan uang koin menjadi lebih cepat dan mudah sehingga waktu dan tenaga yang digunakan lebih sedikit. Serta mengurangi tingkat kesalahan dalam penghitungan dan penyortiran uang koin.
\end{abstract}

Kata-kunci : Prototipe, Arduino, Mikrokontroler, CSCM

\section{Pendahuluan}

\subsection{Latar Belakang Masalah}

Prototipe adalah bentuk dasar atau model awal dari suatu sistem atau bagian dari suatu sistem. Setelah dioperasikan, prototipe ditingkatkan terus sesuai dengan kebutuhan pengguna sistem yang juga meningkat (Kamus Besar Bahasa Indonesia, 2014). Arduino menyatakan perangkat lunak dan perangkat keras yang ditujukan untuk memudahkan siapa saja agar dapat membuat proyek-proyek elektronika dengan mudah dan cepat. Dalam hal ini, papan Arduino menyatakan perangkat keras dan Arduino IDE (Integrated Develpoment Environment) menyatakan perangkat lunak yang digunakan untuk memrogram perangkat keras (Abdul Kadir, 2016). Penyortiran berarti proses, cara, perbuatan menyortir; pemilihan: telah dilakukan penyortiran terhadap surat-surat yang diterima (Kamus Besar Bahasa Indonesia, 2014). Penghitungan memiliki 1 arti. Penghitungan berasal dari kata dasar hitung. Penghitungan memiliki arti dalam kelas nomina atau kata benda sehingga penghitungan dapat menyatakan nama dari seseorang, tempat, atau semua benda dan segala yang dibendakan (Kamus Besar Bahasa Indonesia, 2014).

Dalam kegiatan transaksi di Koperasi Melati seperti simpan pinjam dan menabung, para anggota sering melakukan pembayaran dengan uang koin yang mengakibatkan uang koin menumpuk. Hal tersebut membuat bendahara koperasi kesulitan dalam menghitung uang karena diperlukan waktu yang cukup lama, terlalu banyaknya jumlah elemen yang harus dihitung seperti contohnya uang koin yang berjumlah Rp.10.000 yang terdiri dari 2 keping pecahan uang koin Rp.1000, 12 keping pecahan uang koin Rp.500, 5 keping pecahan uang Rp.200, dan 10 keping pecahan uang Rp.100. Berbeda sekali dengan uang kertas yang bisa hanya terdiri dari 10 atau 5 lembar bahkan bisa hanya terdiri 1 lembar saja.

Bahkan bendahara terkadang melakukan kesalahan menghitung uang koin yang diakibatkan terlalu banyaknya elemen uang koin yang ada. Selain pembayaran anggota, uang koin pun diperlukan untuk digunakan sebagai uang pinjaman anggota, hal tersebut dikarenakan adanya pemotongan uang pinjaman sehingga uang yang dipinjam oleh anggota totalnya tidak utuh dengan jumlah yang dipinjam. Seperti contohnya anggota yang meminjam uang Rp.12.500.000 dilakukan pemotongan $12,5 \%$ yaitu sebesar Rp.1.562.500 sehingga uang pinjaman yang diterima anggota yaitu Rp. 10.937.500.

Berdasarkan beberapa masalah yang telah dikemukakan, maka perlu dibuatkan mesin yang dapat menghitung dan menyortir uang koin untuk mempermudah dalam hal penyortiran dan mengurangi 
kesalahan dalam penghitungan uang koin. Mesin yang dibangun berbasis Arduino, komponen-komponen yang digunakan yaitu Arduino Uno R3, Sensor Infrared, Motor DC, Microcontroller, LCD (liquid cristal display) 20x4, I2C, Keypad 4x4, Motor Servo dan juga software arduino yaitu Arduino IDE yang berisi program untuk menghitung jumlah koin yang telah disortir dan menampilkannya di LCD.

Mesin yang akan dibangun harus bisa mengatasi masalah yang telah dipaparkan diatas yaitu bisa mengefisiensikan waktu penghitungan dan penyortiran, serta mengurangi kesalahan dalam penghitungan yang biasanya dilakukan oleh manusia secara manual.

\subsection{Batasan Masalah}

Agar pembahasan masalah dari Prototipe Mesin CSCM (Coin Sorting and Counting Machine) Berbasis Arduino Uno R3 (Studi Kasus Koperasi Melati) terarah dengan baik, maka dalam laporan ini hanya akan dibahas:

- Mesin penghitung dan penyortiran uang koin/logam saja yang akan dibuat.

- Uang yang dapat dihitung dan disortir hanya sebatas uang rupiah saja, tidak mencakup mata uang asing.

- Mesin hanya dapat digunakan untuk uang koin pecahan Rp.1000 (emisi tahun 2016, dengan spesifikasi berat 4,50 $\pm 0,18 \mathrm{~mm}$, diameter $24,10 \pm$ $0,10 \mathrm{~mm}$, tebal sisi $1,45 \pm 0,10 \mathrm{~mm}), \mathrm{Rp} .500$ (emisi tahun 2016, dengan spesifikasi berat 3,10 \pm $0,05 \mathrm{~mm}$, diameter $27,00 \pm 0,05 \mathrm{~mm}$, tebal sisi 2,35 \pm 0,10 mm ), Rp.200 (emisi tahun 2016, dengan spesifikasi berat $2,38 \pm 0,05 \mathrm{~mm}$, diameter $25,00 \pm 0,05 \mathrm{~mm}$, tebal sisi 2,20 $\pm 0,10 \mathrm{~mm})$, Rp.100 (emisi tahun 2016, dengan spesifikasi berat $1,79 \pm 0,05 \mathrm{~mm}$, diameter 23,00 $\pm 0,05 \mathrm{~mm}$, tebal sisi 2,00 $\pm 0,10 \mathrm{~mm}$ ) saja.

- Jenis uang logam yang dapat dihitung dan disortir adalah jenis uang logam baru yang berwarna putih saja.

- Mesin hanya dapat menghitung dan menyortir uang saja tidak mendeteksi apakah uang itu asli atau palsu.

\section{Tinjauan Pustaka}

\subsection{Uang}

Uang adalah suatu benda yang dapat ditukarkan dengan benda lain, dapat digunakan untuk menilai benda lain, dan dapat disimpan (Solikin, Suseno, 2002). Uang menurut bahan pembuatan, yaitu :

a. Uang logam

Uang logam adalah uang yang terbuat dari logam. Dipilih menggunakan logam karena bisa tahan lama. Pada awal kemunculannya dibuat dengan bahan emas atau perak. Semakin tinggi kadarnya semakin tinggi pula daya tukarnya. Dengan begitu uang seperti ini memiliki tiga nilai: Nilai intrinsik, yaitu nilai bahannya. Nilai nominal, yaitu nilai yang tercetak/tercantum pada uang tersebut. Nilai tukar, yaitu nilai daya tukarnya. Misal Rp500 nilai tukarnya dapat permen, Rp10.000 nilai tukarnya bisa dapat sepiring nasi.

b. Uang kertas

Uang kertas adalah uang yang terbuat dari bahan kertas. Uang jenis ini hanya memiliki nilai nominal dan nilai tukar yang tinggi, sedangkan nilai intrinsiknya tidak. Begitu juga pada zaman sekarang, uang logam dibuat dengan logam biasa sehingga nilai intrinsiknya tidak sebanding dengan nilai nominal.

\subsection{Penghitungan}

Penghitungan memiliki 1 arti. Penghitungan berasal dari kata dasar hitung. Penghitungan memiliki arti dalam kelas nomina atau kata benda sehingga penghitungan dapat menyatakan nama dari seseorang, tempat, atau semua benda dan segala yang dibendakan. Penghitungan berarti proses, cara, perbuatan menghitung, contohnya penghitungan suara untuk memilih ketua baru itu makan waktu satu hari, penghitungan laba rugi, penghitungan cacah jiwa (Kamus Besar Bahasa Indonesia, 2014).

\subsection{Penyortiran}

Penyortiran memiliki 1 arti. Penyortiran berasal dari kata dasar sortir. Penyortiran memiliki arti dalam kelas nomina atau kata benda sehingga penyortiran dapat menyatakan nama dari seseorang, tempat, atau semua benda dan segala yang dibendakan. Penyortiran berarti proses, cara, perbuatan menyortir pemilihan, contohnya telah dilakukan penyortiran terhadap suratsurat yang diterima (Kamus Besar Bahasa Indonesia, 2014).

\subsection{Arduino}

Arduino merupakan sebuah platform yang terdiri dari hardware dan software. Hardware itu sendiri yang disebut microcontroller kemudia software-nya adalah sebuah IDE Arduino yang digunakan untuk memprogram input dan output dari model arduino (Djuanda, Pengenalan Arduino, 2011).

Arduino Uno R3 adalah papan pengembangan mikrokontroler yang berbasis chip ATmega328P. Arduino Uno memiliki 14 digital pin input / output (atau biasa ditulis I/O, dimana 14 pin diantaranya dapat digunakan sebagai output PWM antara lain pin 0 sampai 13), 6 pin input analog, menggunakan crystal $16 \mathrm{MHz}$ antara lain pin A0 sampai A5, koneksi USB, jack listrik, header ICSP dan tombol reset. Hal tersebut adalah semua yang diperlukan untuk mendukung sebuah rangkaian mikrokontroler.

\section{ANALISIS SISTEM}

Analisis sistem adalah penguraian dari suatu kasus yang utuh ke dalam bagian-bagian komponennya denganmaksud untuk mengidentifikasi dan mengevaluasi permasalahan yang terjadi dan kebutuhan 
yang diharapkan sehingga dapat dirancang suatu produk yang sesuai dengan analisis.

\subsection{Analisis Masalah}

Waktu yang diperlukan untuk menghitung uang koin relatif lebih lama dari uang kertas, sebab komponennya lebih banyak. Seperti contohnya menghitung uang koin yang berjumlah Rp.25.000, banyak uang koin yang harus dihitung sehingga menghasilkan jumlah uang sebesar Rp.25.000, yaitu 8 keping uang koin Rp.1000, 25 keping uang koin Rp.500, 10 keping uang koin Rp.200, dan 25 keping uang koin Rp.100. Sedangkan uang kertas yang berjumlah Rp.25.000 bisa hanya selembar uang kertas Rp.20.000 dan Rp.5000 saja. Jumlah uang koin yang paling sedikit pun harus terdiri dari 25 keping uang koin Rp.1000. Dari kasus tersebut bisa disimpulkan bahwa penghitungan uang koin memerlukan lebih banyak waktu daripada penghitungan uang kertas. Selain penghitungan, penyortiran uang koin pun cukup sulit sebab mata kita harus jeli untuk memisahkan mana uang koin Rp.1000, Rp.500, Rp, 200, Rp.100. Walaupun ukurannya berbeda tetapi tidak terlalu jauh bedanya. Di Koperasi Melati, dibutuhkan akurasi kebutuhan uang koin yang digunakan untuk uang kembalian atau pinjaman bagi anggota.

\subsection{Analisis Kebutuhan Sistem}

Analisis kebutuhan yaitu menganalisis kebutuhan yang diperlukan untuk membangun sistem, baik, kebutuhan nonfungsional dan kebutuhan fungsional.

\subsubsection{Kebutuhan Nonfungsional}

Analisa kebutuhan

nonfungsional menggambarkan kebutuhan yang diperlukan untuk menjalankan sistem yang dibangun. Analisis kebutuhan nonfungsional dilakukan untuk mengetahui spesifikasi kebutuhan untuk sistem. Spesifikasi kebutuhan melibatkan analisa perangkat keras (hardware), analisa perangkat lunak (software), dan analisa pengguna (user).

a. Analisa Perangkat Keras

Perangkat keras yang digunakan untuk membangun CSCM (Coin Sorting

and Counting Machine) ini adalah :
a) Microcontroller Arduino Uno R3;
b) Motor DC;
c) Modul Sensor Infrared;
d) Kabel Konektor dan Jumper;
e) LCD 20x4 ;
f) $\mathrm{I} 2 \mathrm{C}$;
g) Keypad 4x4;
h) Motor Servo.

b. Analisa Perangkat Lunak

Perangkat lunak yang digunakan untuk membangun CSCM (Coin Sorting and a) Sistem Operasi Windows

b) Arduino IDE

c) Visual Paradigm

d) Balsamiq Mockup

e) Fritzing

c. Analisa Pengguna

Analisa pengguna menunjukan orang

yang menggunakan CSCM (Coin Sorting and Counting Machine) ini, maka target utama pengguna yang akan menggunakan CSCM ini adalah pengurus Koperasi Melati khusus nya bendahara, CSCM ini pun bisa digunakan oleh pihak lain seperti bank, kasir toko, dan bisa juga digunakan untuk sendiri di rumah.

\subsubsection{Kebutuhan Fungsional}

Pada analisis kebutuhan fungsional ini mendefinisikan fungsi utama CSCM (Coin Sorting and Counting Machine) yang dibangun:

Tabel 1 Kebutuhan Fungsional

\begin{tabular}{|c|l|l|}
\hline No & Kebutuhan & \multicolumn{1}{|c|}{ Keterangan } \\
\hline 1 & $\begin{array}{l}\text { Penyortiran } \\
\text { dan }\end{array}$ & $\begin{array}{l}\text { Tujuan utama pada penelitian ini } \\
\text { Penghitungan } \\
\text { Uang Koin } \\
\text { menghitung uang koin yang } \\
\text { berfungsi untuk efisiensi waktu } \\
\text { dan mengurangi kesalahan dalam } \\
\text { penghitungan uang koin }\end{array}$ \\
\hline 2 & $\begin{array}{l}\text { Antarmuka } \\
\text { Pengguna }\end{array}$ & $\begin{array}{l}\text { LCD ditujukan untuk media } \\
\text { interaksi antara CSCM dan } \\
\text { pengguna melalui LCD ini } \\
\text { pengguna dapat mengatur } \\
\text { CSCM untuk menjalankan } \\
\text { perintah yang diinginkan oleh } \\
\text { pengguna }\end{array}$ \\
\hline 3 & $\begin{array}{l}\text { Pilihan jenis } \\
\text { penghitungan } \\
\text { dan } \\
\text { penyortiran } \\
\text { uang koin } \\
\text { Pengguna dapat memilih jenis } \\
\text { penghitungan dan penyortiran } \\
\text { bisa memilih hitung dan sortir } \\
\text { seluruh uang koin yang } \\
\text { masuk ke CSCM atau hanya } \\
\text { sesuai kebutuhan uang koin saja }\end{array}$ \\
\hline
\end{tabular}

Usecase mendeskripsikan interaksi tipikal antara para pengguna sistem dengan sistem itu sendiri, dengan memberi sebuah narasi tentang bagaimana sistem tersebut digunakan.

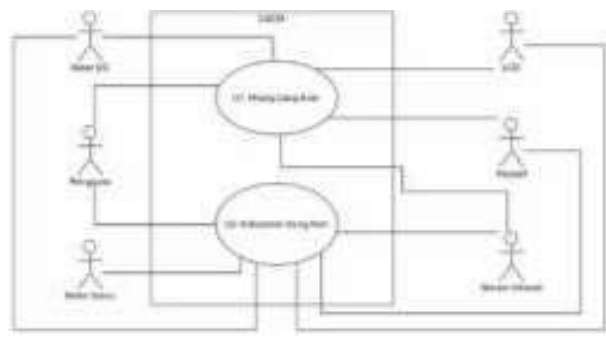


Gambar 2 Use case Diagram CSCM

Berdasarkan Gambar 2 Use Case Diagram CSCM terdapat dua buah us case. Pengguna dapat melakukan fungsi hanya hitung untuk menghitung dan menyortir semua uang koin yang ada diwadah dan kebutuhan uang koin untuk menghitung dan menyortir jumlah uang yang dibutuhkan pengguna saja.

Activity Diagram adalah teknik untuk menggambarkan logika prosedural, proses bisnis, dan jalur kerja. Dalam beberapa hal, diagram ini memainkan peran mirip sebuah diagram alir (Flowchart).

a. Activity Diagram Hitung Uang Koin

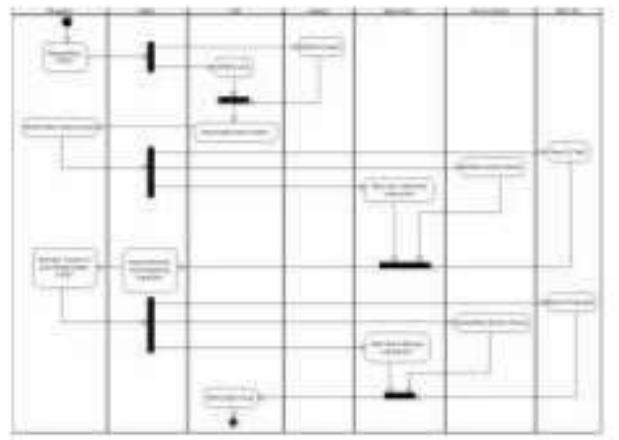

Gambar 3 Activity Diagram Hitung Uang Koin

Activity Diagram Hitung Uang Koin dimulai pada saat pengguna mengaktifkan mesin CSCM lalu sistem mengaktifkan LCD dan Keypad, LCD menampilkan menu utama dan pengguna memilih menu hanya hitung. Kemudian Motor Servo akan berputar membuka lubang koin, Sensor Infrared aktif, dan Motor DC aktif. Setelah itu Sistem menyortir dan menghitung uang koin, setelah koin habis lalu pengguna menekan tombol (X) pada keypad untuk membuat CSCM berhenti bekerja. Setelah pengguna menekan tombolmaka M otor Servo akan berputar ke arah berlawanan untuk menutup lubang koin, Sensor Infrared akan nonaktif, dan Motor DC pun nonaktif. Sistem akan menampilkan hasil penyortiran dan penghitungan pada LCD.

a. Activity Diagram Kebutuhan Uang Koin

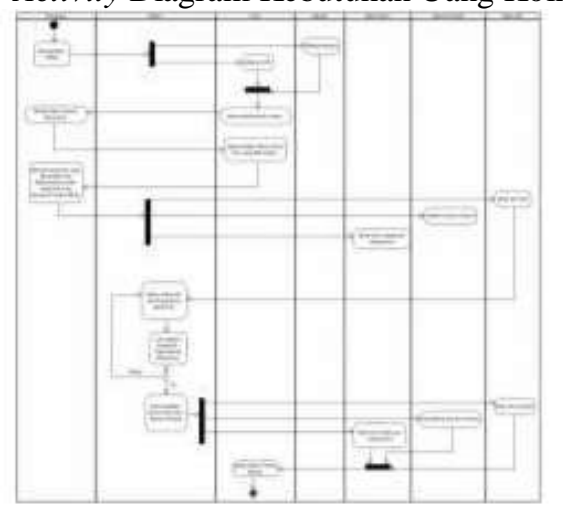

Gambar 4 Activity Diagram Kebutuhan Uang Koin
Activity Diagram Kebutuhan Uang Koin dimulai pada saat pengguna mengaktifkan mesin CSCM lalu sistem mengaktifkan LCD dan Keypad, kemudian sistem menampilkan menu utama pada LCD, pengguna memilih menu sesuai kebutuhan, lalu sistem menampilkan pilihan uang koin mana yang diinginkan, setelah dipilih penguna memasukan jumlah uang koin yang dibutuhkan lalu menekan tombol mulai. Motor Servo akan berputar membuka lubang koin, Sensor Infrared aktif, dan Motor DC aktif. Lalu sistem menghitung dan menyortir uang koin, pada saat sistem menghitung dan menyortir uang koin terjadi decision, jika jumlah uang koin yang dibutuhkan belum sesuai maka sistem akan terus menghitung dan menyortir hingga jumlah uang koin sesuai, jika jumlah uang koin yang dibutuhkan sudah sesuai maka Motor Servo akan berputar berlawanan arah menutup lubang koin, Sensor Infrared nonaktif, dan Motor DC nonaktif. LCD akan menampilkan pesan selesai.

\section{Perancangan Sistem}

Perancangan sistem merupakan suatu proses menyusun suatu konsep berdasarkan hasil analisa yang telah didapatkan. Setelah mengetahui kebutuhan dasar yang dibutuhkan dalam CSCM ini. Maka dilakukanlah sebuah perancangan agar CSCM ini dapat memenuhi kebutuhan dasar tersebut.

\subsection{Perancangan Hardware}

Perancangan hardware pada penelitian ini adalah membuat skema rangkain komponen kelistrikan pada CSCM yang dibangun untuk memberikan gambaran mengenai sistem pada perangkat keras yang akan dibangun. Pada tahap ini pembuatan skema dibuat dengan menggunakan aplikasi Fritzing.

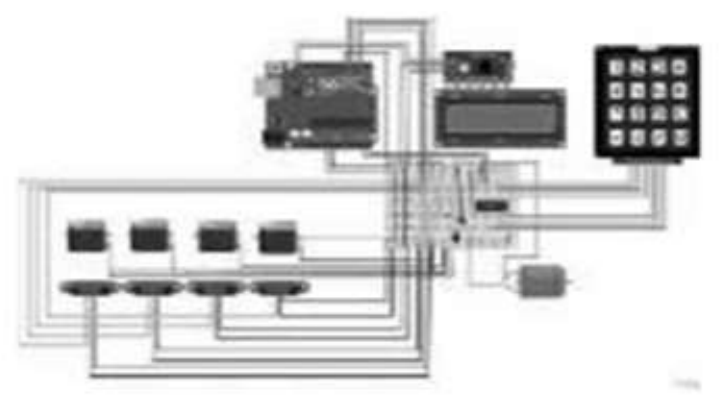

Gambar 5 Perancangan Hardware

Perancangan hardware CSCM terdiri dari beberapa perangkat yaitu Arduino Uno R3, LCD 20x4, I2C, Keypad 4x4, Motor DC, Motor Servo, dan empat buah Sensor Infrared.

\subsection{Perancangan Antarmuka}

Perancangan antarmuka menggambarkan bagaimana CSCM berkomunikasi dengan sistem dan pengguna yang memainkannya. Berikut merupakan rancangan antarmuka dari CSCM :

a. Antarmuka proses menghitung 
Antarmuka proses menghitung merupakan tampilan yang muncul pada saat CSCM sedang melakukan sortir dan hitung uang koin.

\begin{tabular}{|c|}
\hline HITUNG KOIN :: \\
$100: 0200: 0$ \\
$500: 0$ 1000:0 \\
(\#) SELESAI
\end{tabular}

Gambar 6 Antarmuka proses menghitung

b. Antarmuka Kebutuhan Koin

Antarmuka kebutuhan koin merupakan tampilan yang muncul pada saat pengguna memilih menu kebutuhan koin pada menu pilihan.

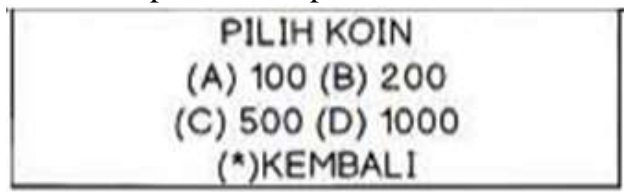

Gambar 6 Antarmuka Kebutuhan Koin

\section{Implementasi Sistem}

Implementasi adalah tahap penerapan sebuah sistem perangkat lunak berdasarkan hasil analisis dan perancangan yang telah dibuat.

\subsection{Implementasi Perangkat Keras}

Pada tahap implementasi dan pengujian, perangkat keras yang digunakan adalah sebagai berikut :

a. Spesifikasi Komputer

- $\quad$ Prosessor : Intel Core I3

- $\quad$ RAM :4GB

- Hardisk : $500 \mathrm{~GB}$

b. Arduino Coin Sorting and Counting Machine

- Arduino Uno R3

- Motor Sevo

- Motor DC

- Modul Sensor Infrared

- LCD 20x4

- $\mathrm{I} 2 \mathrm{C}$

- Keypad 4x4

- Kabel Konektor dan Jumper

\subsection{Implementasi Perangkat Lunak}

$\begin{gathered}\text { Perangkat lunak yang digunakan unt } \\ \text { membangun Prototipe }\end{gathered}$ Coin Sorting and Counting Machine Berbasis Arduino Uno R3 (Studi Kasus Koperasi Melati), terdiri dari :

- $\quad$ Microsoft Windows 8, merupakan sistem operasi yang digunakan pada komputer yang membangun perintah-perintah (syntax) arduino.

- Visual Paradigm 8.0, aplikasi yang digunakan untuk membuat diagram-diagram yang digunakan dalam proses perancangan dan pemodelan sistem.

- Balsamiq Mockups, aplikasi yang digunakan untuk membuat perancangan tampilan antarmuka.
- Fritzing, aplikasi yang digunakan untuk membuat perancangan perangkat keras (hardware).

- Arduino IDE, aplikasi yang digunakan untuk sebagai editor dalam pemrograman/coding arduino.

\subsection{Implementasi Antarmuka}

Berikut ini merupakan implementasi antarmuka dari Coin Sorting and Counting Machine yang telah dibuat.

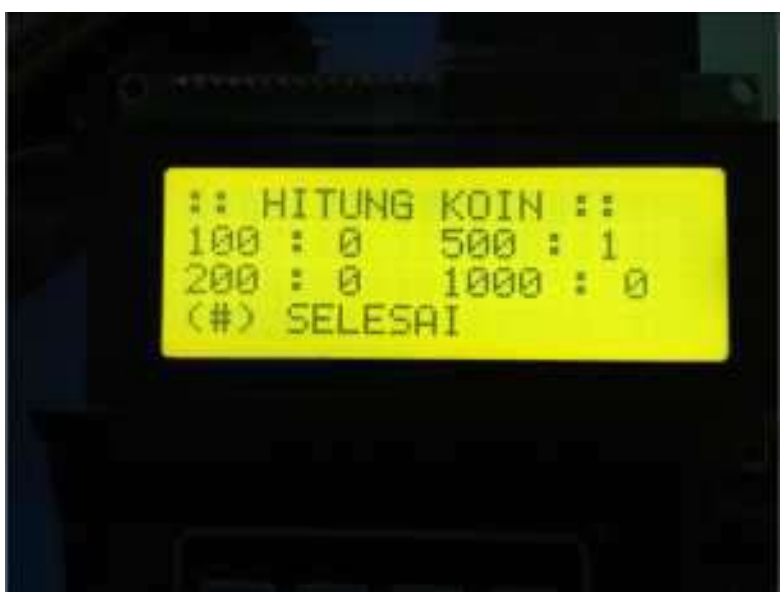

Gambar 7 Antarmuka proses menghitung

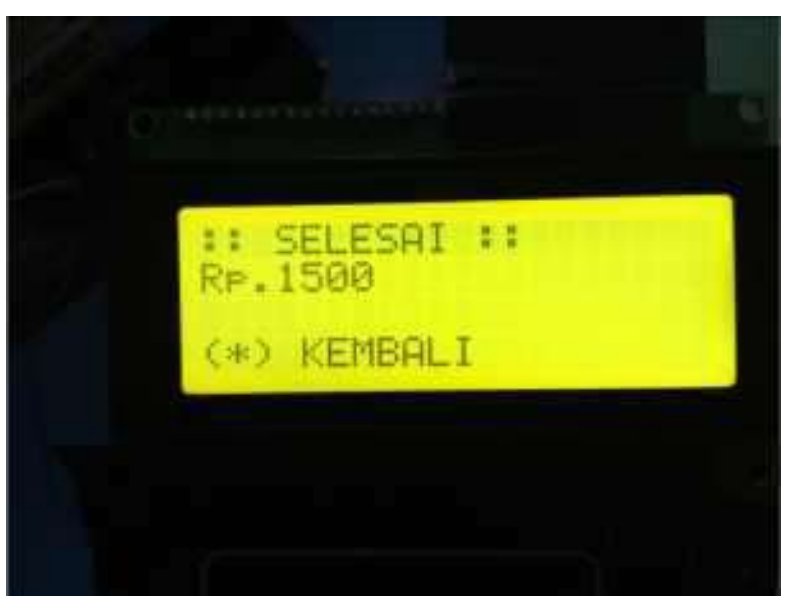

Gambar 8 Antarmuka selesai menghitung 


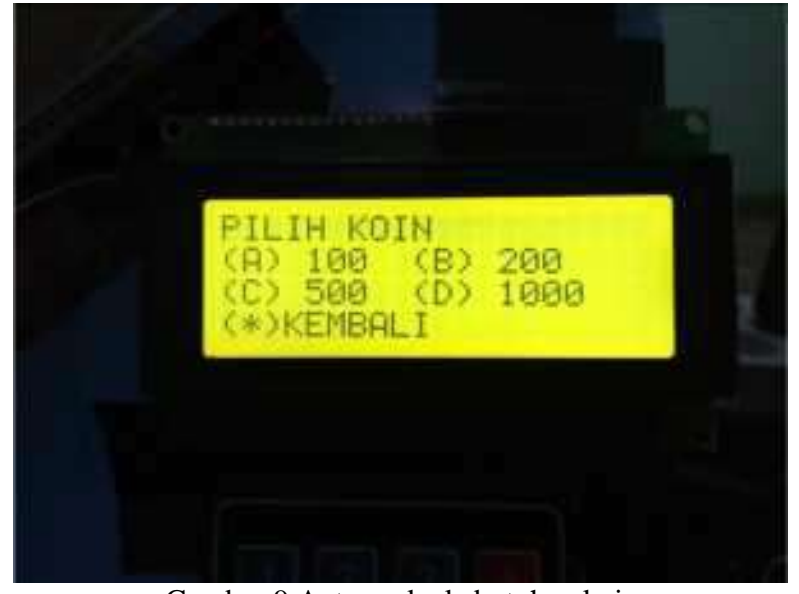

Gambar 9 Antarmuka kebutuhan koin

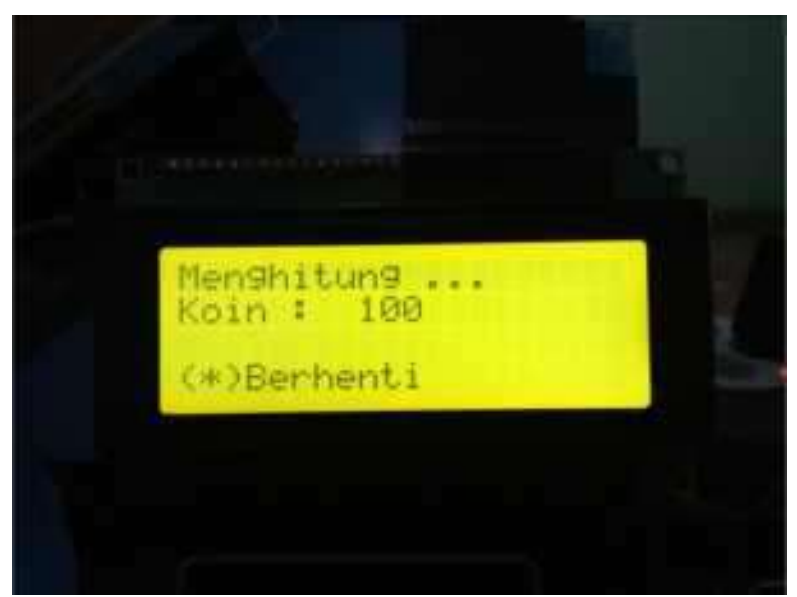

Gambar 10 Antarmuka menghitung koin

\section{Pengujian Sistem}

Pengujian merupakan bagian yang penting dan siklus pengembangan atau pembuatan perangkat lunak. Pengujian berikut dilakukan untuk menjamin bahwa setiap fungsi dan modul CSCM ini dapat berjalan sebagaimana mestinya. Pengujian sistem CSCM ini dulakukan menggunakan metode black box.

\begin{tabular}{|l|l|l|c|}
\hline Pengujian & \multicolumn{1}{|c|}{ Keterangan } & \multicolumn{1}{|c|}{$\begin{array}{l}\text { Hasil yang } \\
\text { diharapkan }\end{array}$} & $\begin{array}{c}\text { Hasil } \\
\text { akhir }\end{array}$ \\
\hline $\begin{array}{l}\text { Splash } \\
\text { screen }\end{array}$ & $\begin{array}{l}\text { Pengguna } \\
\text { menghidupkan } \\
\text { CSCM }\end{array}$ & $\begin{array}{l}\text { LCD sesuai } \\
\text { menampilkan } \\
\text { splash screen } \\
\text { dalam beberapa } \\
\text { detik dan } \\
\text { kemudian } \\
\text { menampilkan } \\
\text { menu utama }\end{array}$ & \\
\hline utama & $\begin{array}{l}\text { Pengguna } \\
\text { menghidupkan } \\
\text { CSCM dan } \\
\text { memilih salah } \\
\text { satu menu } \\
\text { dengan } \\
\text { menekan } \\
\text { tombol pada } \\
\text { keypad }\end{array}$ & $\begin{array}{l}\text { LCD } \\
\text { menampilkan } \\
\text { dan utama } \\
\text { dapat berfungsi }\end{array}$ & sesuai \\
\end{tabular}

\begin{tabular}{|c|c|c|c|}
\hline Pengujian & Keterangan & $\begin{array}{l}\text { Hasil yang } \\
\text { diharapkan }\end{array}$ & $\begin{array}{l}\text { Hasil } \\
\text { akhir }\end{array}$ \\
\hline $\begin{array}{l}\text { Menu } \\
\text { hanya } \\
\text { hitung }\end{array}$ & $\begin{array}{l}\text { Pengguna } \\
\text { memilih } \\
\text { menu hanya } \\
\text { hitung dengan } \\
\text { menekan } \\
\text { tombol (A) } \\
\text { pada keypad }\end{array}$ & $\begin{array}{l}\text { LCD } \\
\text { menampilkan } \\
\text { proses hitung } \\
\text { uang koin, } \\
\text { Motor DC } \\
\text { bergerak, } \\
\text { Sensor Infrared } \\
\text { aktif, Motor } \\
\text { Servo terbuka }\end{array}$ & sesuai \\
\hline $\begin{array}{l}\text { Menu } \\
\text { sesuai } \\
\text { kebutuhan }\end{array}$ & $\begin{array}{l}\text { Pengguna } \\
\text { memilih } \\
\text { menu sesuai } \\
\text { kebutuhan } \\
\text { dengan } \\
\text { menekan } \\
\text { tombol (B) } \\
\text { Sesuai } \\
\text { Kebutuhan } \\
\text { pada } \\
\text { keypad }\end{array}$ & $\begin{array}{l}\text { LCD } \\
\text { menampilkan } \\
\text { Pilihan } \\
\text { Koin }\end{array}$ & sesuai \\
\hline
\end{tabular}

\section{Kesimpulan}

Berdasarkan hasil penelitian, perancangan dan implementasi yang dilakukan, dapat diambil beberapa kesimpulan, antara lain :

- Waktu yang dibutuhkan untuk menghitung dan menyortir uang koin lebih efisiensi (cepat dan mudah).

- Dapat mengurangi kesalahan dalam penghitungan uang koin.

- Dapat menghitung akurasi kebutuhan uang koin.

\section{Saran}

Pada penelitian ini terdapat beberapa saran untuk meningkatkan kinerja dari hasil perancangan Prototipe Coin Sorting and Counting Machine yang dibangun selanjutnya, yaitu :

- Mesin yang dibuat tidak hanya bisa digunakan untuk menghitung dan menyortir uang koin logam saja.

- Mesin bisa menghitung dan menyortir uang dari negara manapun, tidak hanya rupiah saja.

- Mesin dapat menghitung dan menyortir uang koin dari emisi tahun berapapun.

- Jenis logam uang koin apapun dapat dihitung dan disortir.

- Mesin dapat mendeteksi keaslian uang yang masuk.

- Mesin dapat menampung lebih banyak uang koin.

- Mesin dapat memenuhi kebutuhan uang koin setiap nominal langsung dalam satu kali proses.

- Penggunaan bahan yang tepat agar lebih presisi dalam ukurannya.

- Perhitungan lubang-lubang koin dan penempatan alat lebih presisi lagi sehingga mengurangi kesalahan. 


\section{Daftar Pustaka}

[1] Afrie Setiawan. (2011). 20 Aplikasi Mikrokontroler ATMega 8535 ATMega $16 \quad$ Menggunakan Bascom- AVR. Yogyakarta: Andi.

[2] Didit Haryadi. (2012). Studi Pemilihan Motor DC dan Kapasitasnya pada Mobil Listrik. Universitas Sriwijaya, Jurusan Teknik Elektro Fakultas Teknik.

[3] Djuanda, F. (2011). Pengenalan Arduino. Jakarta: TOBUKU.

[4] Fina, Achmad. (2014). Rancang Bangun Miniatur Mesin Otomatis Minuman Kaleng Berbasis Arduino Uno. Universitas Mercubuana, Jurusan Teknik Elektro Fakultas Teknik.

[5] Fowler, M. (2005).UML Distille Edisi 3 Panduan Singkat Bahasa Pemodelan Objek Standar. Yogyakarta: ANDI.

[6] Geetech. (2013). Arduino Infraredproximity. From http://www.geeetech.com/wiki/index.php/Arduino Infrared_proximity_switch_module, 20 Desember 2016.

[7] Heryanto, Ary M. (2008). Pemrograman Bahasa C untu Mikrokontroller ATMega853. Yogyakarta: Andi Offset.

[8] Moh. Ibnu Malik, ST dan Mohammad Unggul Juwana. 2009. Aneka Proyek Mikrokontroler PIC16F84A. PT Elex Media Komputindo. Jakarta.

[9] Kadir, A. (2016). Scratch for Arduino (SA4). Yogyakarta: CV. Andi Offset.

[10] Kadir, A. (2016). Simulasi Arduino. Jakarta: PT.Elex Media Komputindo.

[11] Karyanto Sari. (2012). Prototipe Mesin Penyeleksi dan Penghitung Uang Logam Berbasis Mikrokontroler ATMEL AVR AT90S8515. Universitas Diponegoro, Jurusan Teknik Elektro Fakultas Teknik.

[12] Nalaprana, Sri. (2015). Analisa Motor DC (Direct Current) Sebagai Penggerak Mobil Listrik. Universitas Sriwijaya, Jurusan Teknik Elektro Fakultas Teknik.

[13] Natalino, Nuncio. (2017). Modul Komunikasi Serial Pada Model Simulator Boiler Berbasi Mikrokontroler ATMegal6. Universitas Sanata Dharma, Jurusan Teknik Elektro Fakultas Sains dan Teknologi.

[14] Pressman, R. S. (2010). Rekayasa Perangkat Lunak Buku Satu. Yogyakarta : Andi.

[15] Santoso, H. (2015). Panduan Praktis Arduino Untuk Pemula V.1. Jakarta : Elang Sakti.

[16] Setiawan, H. (2014). Rancang Bangun Konveyor Untuk Mengetahui Hasil Output Produksi Menggunakan Arduino Uno dan C\#.Net.
Universitas Mercubuana, Jurusan Teknik Elektro Fakultas Teknik.

[17] Solikin, Suseno. 2002. Uang : Pengertian, penciptaan dan peranannya dalam perekonomian. Jakarta : Pusat Pendidikan dan Studi Kebanksentralan (PSSK) BI.

[18] Supegina Fina. 2014. Rancang Bangun Miniatur Mesin Otomatis Minuman Kaleng Berbasis Arduino Uno. Universitas Mercu Buana, Program Studi Teknik Elektro Fakultas Teknik.

[19] Sutono. 2013. Sistem Monitoring Ketinggian Air. Universitas Komputer Indonesia, Program Studi Teknik Komputer Fakultas Teknik dan Ilmu Komputer.

[20] Verdi Yasin. 2012. Rekayasa Perangkat Lunak Berorientasi Objek Mitra Wancana Media. Jakarta 